\title{
Dietary total antioxidant capacity and obesity in children and adolescents
}

\section{Running head: Dietary TAC and obesity in childhood}

\section{BLANCA PUCHAU ${ }^{1}$, MARÍA C OCHOA ${ }^{1}$, M $^{\mathrm{a}}$ ÁNGELES ZULET ${ }^{1}$, AMELIA} MARTI $^{1}, \mathrm{~J}_{\text {ALFREDO MARTÍNEZ }}{ }^{1}$, GENOI MEMBERS ${ }^{2}$

${ }^{1}$ Department of Nutrition and Food Science, Physiology and Toxicology, University of Navarra, Irunlarrea 1, 31008 Pamplona, Spain.

${ }^{2}$ Other members of GENOI are C. Azcona, M.A. Martínez-González, M.J. MorenoAliaga, M. Chueca, M. Oyarzabal, A. Patiño and R. Pelach.

\begin{abstract}
Dietary antioxidant intake has been suggested to protect against oxidative damage and related clinical complications. The aim of this study was to assess the potential relationships between the dietary total antioxidant capacity (TAC) and obesity-related features in children and adolescents.

Anthropometric variables from 369 children and adolescents were measured (184 obese and 185 control). A validated food-frequency questionnaire was used to calculate the TAC and the daily nutrient and energy intake.

Dietary TAC showed positive associations with fiber, folic acid, magnesium, and vitamins A, C and E. BMI, SDS-BMI and total body fat were inversely associated with dietary TAC only in obese subjects.

These data suggest that dietary TAC may be a potential indicator of the risk to develop obesity-related features and could be considered as a useful method in assessing antioxidant intake.
\end{abstract}


Keywords: Total antioxidant capacity, oxidative stress, childhood obesity, foodfrequency questionnaire, diet, body weight homeostasis.

Abbreviations: BMI: body mass index; FFQ: food-frequency questionnaire; FRAP: ferric reducing-antioxidant power; HDL: high-density lipoprotein cholesterol; HOMAIR: homeostasis model assessment of insulin resistance; LDL: low-density lipoprotein; SDS-BMI: standard deviation score of body mass index; SUN: Seguimiento Universidad de Navarra; TAC: total antioxidant capacity.

Correspondence: J. Alfredo Martínez. Department of Nutrition and Food Science, Physiology and Toxicology, University of Navarra, Irunlarrea 1, 31008 Pamplona, Spain. Tel.: +34 9484256 00. Fax: +34 9484256 19. E-mail: jalfmtz@unav.es.

\section{Background}

A positive energy balance between amounts of energy consumed over the energy spent in everyday life underlies weight gain. In this context, at least 155 million school-age children worldwide are overweight or obese, according to the latest estimates from the International Obesity TaskForce (Ochoa et al. 2007) and incidence rates are increasing dramatically every year (Lobstein et al. 2003). In adolescents, the problem is particularly difficult to treat since overeating is related to a lack of physical activity, as boosted by modern lifestyles (Kimm et al. 2002; Kohn et al. 2006). Some research guidelines recommend identifying and testing specific components of physical activity and diet programs for obese children (Pratt et al. 2008). Dietary interventions are aimed at reducing the intake of high-fat foods, simple sugars and sweetened beverages while 
increasing the consumption of low-calorie and high-fiber foods such as fruits, vegetables and whole grains (Singhal et al. 2007).

The role of oxidative stress on several chronic diseases is receiving increasing attention due to identified links with chronic diseases such as obesity, hypertension, dislypidemia or type 2 diabetes (Fulop et al. 2006). Indeed, there is a relationship between food intake and oxidative stress modulation (Mohanty et al. 2000; Mohanty et al. 2002), being described that energy restriction might decrease the levels of oxidative stress mediators (Dandona et al. 2001). Furthermore, antioxidant intake has been suggested to protect against oxidative damage and related complications (Puchau et al. 2009b; Puchau et al. 2009c). There are some studies relating oxidative stress to obesity and metabolic syndrome in children and adolescents (Codoner-Franch et al. 2009; Molnar et al. 2004), but they include a small number of subjects and their findings must be corroborated by larger trials in different populations. Moreover, such studies include some single dietary antioxidants or oxidative stress markers, whereas this study introduces the total antioxidant capacity (TAC) concept in order to reflect the total antioxidant power intake (Serafini and Del Rio 2004). Additionally, dietary TAC has been proved to be a useful tool for investigating the potential healthy effects of dietary antioxidants occurring in mixed diets (Brighenti et al. 2005). Thus, the objective of this study was to assess the potential relationships between dietary TAC and obesity-related markers in obese children and adolescents.

\section{Methods}

\subsection{Subjects}

The study sample ( $n=369)$ was recruited from the paediatric departments at the Virgen del Camino Hospital, University Hospital and other primary health care centres, and 
included children and adolescents (6-18 years old). The obese group ( $n=184)$ consisted of subjects with body mass index (BMI) above the 97th percentile of the Spanish BMI reference data for age and gender (Ochoa et al. 2004). If we had used the International Obesity TaskForce standards, only $71 \%$ of Spanish obese children would have been classified as such (Cole et al. 2000). Exclusion criteria were exposure to hormonal treatment or development of secondary obesity due to endocrinopathy or serious undercurrent illness. Subjects were recruited when they attended primary health care centres for routine medical examinations or vaccinations. All participants and their parents provided informed consent to participate after a clear explanation of the study protocol, which was previously approved by the Ethics Committee of the University of Navarra.

Two trained research scientists conducted face-to-face interviews with participants and their parents (father, mother, or tutor). The ratio between METs h/week in physical activity and the time spent sitting down during leisure time (S) was used to predict recreational energy expenditure (Ochoa et al. 2004). The questionnaire included 17 activities selected from sports and games and 10 response categories for frequency, ranging from "never" to "eleven hours or more per week." Sedentary lifestyle was assessed through the number of hours spent watching television and videos during schooldays and on the weekends. Moreover, information about the participant's family history of obesity was obtained. Family history of obesity was considered when the father or the mother of the proband was obese $\left(\mathrm{BMI}>30 \mathrm{~kg} / \mathrm{m}^{2}\right)$.

\subsection{Anthropometric and body composition measurements}

All anthropometric measurements were carried out with the subjects barefoot, wearing only their underwear following standardized protocols (Gibson 2005). Body weight was measured to the nearest $0.1 \mathrm{~kg}$ and body fat to the nearest $0.1 \%$ by using a Tanita TBF 
300 (Tanita Corp., Arlington Heights, IL, USA). BMI was calculated accordingly body weight divided by squared height $\left(\mathrm{kg} / \mathrm{m}^{2}\right)$.

\subsection{Dietary intake assessment}

The habitual diet was assessed with the semi-quantitative 136-item SUN (Seguimiento Universidad de Navarra) food-frequency questionnaire (FFQ) previously validated in Spain for energy and nutrient intake (Martin-Moreno et al. 1993).

The dietary TAC value was calculated by adding the TAC values from the ferric reducing-antioxidant power (FRAP) assay of each food as previously reported (Halvorsen et al. 2002; Halvorsen et al. 2006; Pellegrini et al. 2003; Pellegrini et al. 2006; Salvatore et al. 2005), and was expressed as TAC in mmol/100 g of food. To assign a value to TAC-providing foods not available in previous reports, the data for a similar food item (e.g., same botanical group) were used as a proxy. When TAC values of cooked food were not available, TAC values of fresh food were used to calculate TAC value. The mean of TAC values of foods contained in each item of the SUN FFQ was used to calculate dietary TAC value from this food questionnaire (Puchau et al. 2009a). The TAC values from the SUN FFQ were used to assess the associations with obesity-related features.

\subsection{Analyses of biological samples}

All blood samples were drawn after an overnight (12-h) fast, centrifuged immediately for $15 \mathrm{~min}$ at $2205 \mathrm{~g}$ and $4^{\circ} \mathrm{C}$, and stored at $-80^{\circ} \mathrm{C}$. Serum glucose, triacylglycerols, total cholesterol and high-density lipoprotein cholesterol (HDL-c), were assessed by an automatized colorimetric assay (COBAS MIRA, Roche, Basel, Switzerland) with specific commercial kits (ABX Pentra, Roche, Basel, Switzerland). The reported serum low-density lipoprotein cholesterol (LDL-c) data were calculated by the Friedewald 
equation as described elsewhere (Friedewald et al. 1972). Serum insulin was measured by radioimmunoassay (TKIN1 kit, Diagnostic Products, Madrid, Spain). For estimating insulin sensitivity, the homeostasis model assessment of insulin resistance (HOMA-IR) (glucose concentration $\mathrm{x}$ insulin concentration/22.5) was calculated (Matthews et al. 1985).

\subsection{Statistical analyses}

The Shapiro-Wilk test was used to determine variable distribution. Accordingly, the parametric Student's $t$ test or Mann-Whitney's $U$ test were performed to detect significant differences between subjects with dietary TAC values higher and lower than the median value (cut-off 7.8 and $7.0 \mathrm{mmol}$ for control and obese subjects, respectively). Partial correlations adjusted by age, sex and daily energy intake were performed to evaluate relationships between variables. A multivariate linear regression model was performed to further explain associations between variables. Results are reported as mean \pm standard deviation, while confidence intervals (95\% CI) are used to describe linear regression coefficient (B) values. Statistical analysis were performed by using SPSS version 15.0 (SPSS Inc., Chicago, IL, USA) for Windows XP (Microsoft, Redmond, WA, USA). Data were considered statistically significant for $p$ values below 0.05 .

\section{Results}

Anthropometric, biochemical, lifestyle and dietary characteristics of control and obese children and adolescents are presented in Table I. As expected, anthropometric measurements showed statistically significant differences between obese and control subjects. Moreover, obese subjects presented higher values of circulating leptin, glucose, insulin, triglycerides as well as the HDL and the LDL fractions of cholesterol, 
although total cholesterol did not reached statistical significance. Regarding lifestyle and dietary habits, control subjects showed higher levels of physical activity and total energy intake as well as a higher consumption of dietary antioxidants than obese subjects.

[Insert Table I about here]

\subsection{Dietary TAC as a measurement of antioxidant intake}

Partial correlations were carried out between dietary TAC values and antioxidant intake (Table II). Fiber, folic acid, vitamins A, C and E showed a positive and significant correlation with dietary TAC values after adjusting for age, sex and daily energy intake. The same correlation was followed by fiber from different sources (vegetables, fruits and legumes), whereas fiber from cereals showed negative and significant correlations with dietary TAC after adjusting for age, sex and daily energy intake.

[Insert Table II about here]

\subsection{Dietary TAC and obesity-related markers}

In the group of obese subjects, relevant statistically significant differences were found for anthropometric variables such as total body fat (Figure 1) and BMI, but not for the standard deviation score of body mass index (SDS-BMI), between subjects with higher and lower dietary TAC values than the median (Table III). Some biochemical measurements concerning glucose and lipid metabolism followed similar trends, but did not achieve statistical significance when the obese group was splited by the dietary TAC value. No remarkable differences were found for the control group after applying the dietary TAC categorization criterion. Regarding the lifestyle features, both groups showed higher physical activity ratios and energy intakes when dietary [Insert Table III about here] 
TAC was above the median. To further investigate the relationships among anthropometric markers and the dietary TAC value as a continuous variable in the obese group of subjects, a multivariate linear regression analysis was performed (Table IV). BMI, SDS-BMI and total body fat showed to be inversely associated with dietary TAC independently of age, sex, daily energy intake, family history of obesity and physical activity ratio. Regarding TAC coefficient values, total body fat was the obesity-related feature with a higher association with dietary TAC.

[Insert Table IV about here]

\section{Discussion}

In order to assess the dietary antioxidant intake, it has been lately described a FFQ able to determine the dietary TAC intake in different samples of subjects in a reliable manner (Pellegrini et al. 2007; Rautiainen et al. 2008). In this context, we performed similar calculations using the FFQ from the SUN study, which has been previously validated for estimating nutrients intake (Martin-Moreno et al. 1993) and the dietary TAC value (Puchau et al. 2009a). The TAC intake has been highly related with the consumption of some specific food groups as vegetables, fruits and legumes (Rautiainen et al. 2008), which are among the most important contributors of dietary antioxidant nutrients or components (Agudo et al. 2007). Thus, our study reported a positive association between dietary TAC values and the intake of some antioxidant nutrients. Fiber from cereal sources was negatively correlated with dietary TAC. The lack of a positive association can be explained by the fact that this group does not refer only to whole cereals but also to refined and cereal products as well as some sugar-rich baked goods. Furthermore, a recent study has proposed that dietary TAC is positively associated with plasma TAC (Puchau et al. 2009a), suggesting that dietary TAC may constitute a useful tool in antioxidant intake assessment. 
The role of oxidative processes on several chronic diseases is receiving increasing attention due to their links with obesity, atherosclerosis or type 2 diabetes (Brenneisen et al. 2005), and to the association of metabolic syndrome features with oxidative and inflammatory biomarkers (Dandona et al. 2004). Although the molecular mechanisms have not been fully elucidated, oxidative stress accompanying obesity and its complications has shown to be reduced by weight loss, caloric restriction or antioxidant-rich diets (Vincent and Taylor 2006) that may modulate the synthesis of inflammatory markers and contribute to the total antioxidant capacity of a diet (Brighenti et al. 2005), highlighting the relationships between obesity-related inflammation and concentrations of antioxidants.

To our knowledge, this is the first study designed to evaluate the relationships between dietary TAC and childhood obesity. Interestingly, we found an inverse and strong association between BMI as well as SDS-BMI and total body fat, three typical adiposity markers, with dietary TAC. Our results are in accordance with another study linking high SDS-BMI values to higher levels of markers of oxidative stress damage in children (Codoner-Franch et al. 2009). In this context, oxidative stress has been related to metabolic syndrome-related diseases such as obesity and type 2 diabetes (Dandona et al. 2004). Thus, although we did not achieve a statistical significance for every biochemical and obesity-related measurements, a previous study in young adults showed an inverse association between dietary TAC and serum free fatty acids and glucose (Puchau et al. 2009a), which are early markers of metabolic syndrome features. Furthermore, an energy intake restriction has been associated with a decreased oxidative stress and a diminished metabolic syndrome occurrence in obese adults (Skalicky et al. 2009). The present study reports an inverse association between obesity-related markers and dietary TAC values in obese subjects, suggesting a possible role of antioxidant 
dietary consumption in weight homeostasis independently of daily energy intake. However, further studies are needed to confirm these data and to widen these results to other obesity-related parameters.

In conclusion, these data suggest that dietary TAC, as a novel measurement of antioxidant intake, may be also a potential predictor of the risk to develop obesityrelated features such as BMI, SDS-BMI and total body fat in obese children and adolescents. Indeed, dietary TAC values could represent a research tool to investigate the antioxidant intake and its possible approach to a novel obesity treatment.

\section{Acknowledgements}

The authors are grateful for the participation of subjects and their families and the collaboration of the medical teams from the Virgen del Camino Hospital, University Clinic and Health Centre of Barañain. This work has been supported by Ibercaja, CIBERobn, which is an initiative of the ISC-III (CB06/03/1017), the Línea Especial about Nutrition, Obesity and Health (University of Navarra LE/97) and the Asociación de Amigos fellowships scheme of the University of Navarra. 


\section{References}

Agudo A, Cabrera L, Amiano P, Ardanaz E, Barricarte A, Berenguer T, Chirlaque MD, Dorronsoro M, Jakszyn P, Larranaga N, Martinez C, Navarro C, Quiros JR, Sanchez MJ, Tormo MJ, Gonzalez CA. 2007. Fruit and vegetable intakes, dietary antioxidant nutrients, and total mortality in Spanish adults: findings from the Spanish cohort of the European Prospective Investigation into Cancer and Nutrition (EPIC-Spain). Am J Clin Nutr 85:1634-42.

Brighenti F, Valtuena S, Pellegrini N, Ardigo D, Del Rio D, Salvatore S, Piatti P, Serafini M, Zavaroni I. 2005. Total antioxidant capacity of the diet is inversely and independently related to plasma concentration of high-sensitivity C-reactive protein in adult Italian subjects. Br J Nutr 93:619-25.

Brenneisen P, Steinbrenner H, Sies H. 2005. Selenium, oxidative stress, and health aspects. Mol Aspects Med, 26: 256-267.

Codoner-Franch P, Boix-Garcia L, Simo-Jorda R, Del Castillo-Villaescusa C, MasetMaldonado J, Valls-Belles V. 2009. Is obesity associated with oxidative stress in children? Int J Pediatr Obes 1-8.

Cole TJ, Bellizzi MC, Flegal KM, Dietz WH. 2000. Establishing a standard definition for child overweight and obesity worldwide: international survey. Bmj 320:1240-3.

Dandona P, Mohanty P, Hamouda W, Ghanim H, Aljada A, Garg R, Kumar V. 2001. Inhibitory effect of a two day fast on reactive oxygen species (ROS) generation by leucocytes and plasma ortho-tyrosine and meta-tyrosine concentrations. J Clin Endocrinol Metab 86:2899-902. 
Dandona P, Aljada A, Bandyopadhyay A. 2004. Inflammation: the link between insulin resistance, obesity and diabetes. Trends Immunol 25:4-7.

Friedewald WT, Levy RI, Fredrickson DS. 1972. Estimation of the concentration of low-density lipoprotein cholesterol in plasma, without use of the preparative ultracentrifuge. Clin Chem 18:499-502.

Fulop T, Tessier D, Carpentier A. 2006. The metabolic syndrome. Pathol Biol (Paris) 54:375-86.

Gibson RS. 2005. Principles of nutritional assessment. 2nd ed. New York: Oxford University Press.

Halvorsen BL, Holte K, Myhrstad MC, Barikmo I, Hvattum E, Remberg SF, Wold AB, Haffner K, Baugerod H, Andersen LF, Moskaug O, Jacobs DR, Jr., Blomhoff R. 2002. A systematic screening of total antioxidants in dietary plants. J Nutr 132:461-71.

Halvorsen BL, Carlsen MH, Phillips KM, Bohn SK, Holte K, Jacobs DR, Jr., Blomhoff R. 2006. Content of redox-active compounds (ie, antioxidants) in foods consumed in the United States. Am J Clin Nutr 84:95-135.

Kimm SY, Glynn NW, Kriska AM, Barton BA, Kronsberg SS, Daniels SR, Crawford PB, Sabry ZI, Liu K. 2002. Decline in physical activity in black girls and white girls during adolescence. N Engl J Med 347:709-15.

Kohn M, Rees JM, Brill S, Fonseca H, Jacobson M, Katzman DK, Loghmani ES, Neumark-Sztainer D, Schneider M. 2006. Preventing and treating adolescent obesity: a position paper of the Society for Adolescent Medicine. J Adolesc Health 38:784-7. 
Lobstein TJ, James WP, Cole TJ. 2003. Increasing levels of excess weight among children in England. Int J Obes Relat Metab Disord 27:1136-8.

Martin-Moreno JM, Boyle P, Gorgojo L, Maisonneuve P, Fernandez-Rodriguez JC, Salvini S, Willett WC. 1993. Development and validation of a food frequency questionnaire in Spain. Int J Epidemiol 22:512-9.

Matthews DR, Hosker JP, Rudenski AS, Naylor BA, Treacher DF, Turner RC. 1985. Homeostasis model assessment: insulin resistance and beta-cell function from fasting glucose and insulin concentrations in men. Diabetologia 28:412-9.

Mohanty P, Hamouda W, Garg R, Aljada A, Ghanim H, Dandona P. 2000. Glucose challenge stimulates reactive oxygen species (ROS) generation by leucocytes. J Clin Endocrinol Metab 85:2970-3.

Mohanty P, Ghanim H, Hamouda W, Aljada A, Garg R, Dandona P. 2002. Both lipid and protein intakes stimulate increased generation of reactive oxygen species by polymorphonuclear leukocytes and mononuclear cells. Am J Clin Nutr 75:767-72.

Molnar D, Decsi T, Koletzko B. 2004. Reduced antioxidant status in obese children with multimetabolic syndrome. Int J Obes Relat Metab Disord 28:1197-202.

Ochoa MC, Marti A, Azcona C, Chueca M, Oyarzabal M, Pelach R, Patino A, MorenoAliaga MJ, Martinez-Gonzalez MA, Martinez JA. 2004. Gene-gene interaction between PPAR gamma 2 and ADR beta 3 increases obesity risk in children and adolescents. Int $\mathrm{J}$ Obes Relat Metab Disord 28 Suppl 3:S37-41. 
Ochoa MC, Moreno-Aliaga MJ, Martinez-Gonzalez MA, Martinez JA, Marti A. 2007. Predictor factors for childhood obesity in a Spanish case-control study. Nutrition 23:379-84.

Pellegrini N, Serafini M, Colombi B, Del Rio D, Salvatore S, Bianchi M, Brighenti F. 2003. Total antioxidant capacity of plant foods, beverages and oils consumed in Italy assessed by three different in vitro assays. J Nutr 133:2812-9.

Pellegrini N, Serafini M, Salvatore S, Del Rio D, Bianchi M, Brighenti F. 2006. Total antioxidant capacity of spices, dried fruits, nuts, pulses, cereals and sweets consumed in Italy assessed by three different in vitro assays. Mol Nutr Food Res 50:1030-8.

Pellegrini N, Salvatore S, Valtuena S, Bedogni G, Porrini M, Pala V, Del Rio D, Sieri S, Miglio C, Krogh V, Zavaroni I, Brighenti F. 2007. Development and validation of a food frequency questionnaire for the assessment of dietary total antioxidant capacity. $\mathrm{J}$ Nutr 137:93-8.

Pratt CA, Stevens J, Daniels S. 2008. Childhood obesity prevention and treatment: recommendations for future research. Am J Prev Med 35:249-52.

Puchau B, Zulet MA, González de Echávarri A, Hermsdorff HHM, Martinez JA. 2009a. Dietary total antioxidant capacity is negatively associated with some metabolic syndrome features. Nutrition

Puchau B, Zulet MA, González de Echávarri A, Navarro-Blasco I, Martinez JA. 2009b. Selenium intake reduces serum C3, an early marker of metabolic syndrome manifestations, in healthy young adults. Eur J Clin Nutr 63:858-64. 
Puchau B, Zulet MA, Urtiaga G, Navarro-Blasco I, Martinez JA. 2009c. Asymmetric dimethylarginine association with antioxidants intake in healthy young adults: a role as an indicator of metabolic syndrome features. Metabolism

Rautiainen S, Serafini M, Morgenstern R, Prior RL, Wolk A. 2008. The validity and reproducibility of food-frequency questionnaire-based total antioxidant capacity estimates in Swedish women. Am J Clin Nutr 87:1247-53.

Salvatore S, Pellegrini N, Brenna OV, Del Rio D, Frasca G, Brighenti F, Tumino R. 2005. Antioxidant characterization of some Sicilian edible wild greens. J Agric Food Chem 53:9465-71.

Serafini M, Del Rio D. 2004. Understanding the association between dietary antioxidants, redox status and disease: is the Total Antioxidant Capacity the right tool? Redox Rep 9:145-52.

Singhal V, Schwenk WF, Kumar S. 2007. Evaluation and management of childhood and adolescent obesity. Mayo Clin Proc 82:1258-64.

Skalicky J, Muzakova V, Kandar R, Meloun M, Rousar T. 2009. Oxidative stress and metabolic syndrome in obese adults with and without controlled diet restriction. Bratisl Lek Listy 110:152-7.

Vincent HK, Taylor AG. 2006. Biomarkers and potential mechanisms of obesityinduced oxidant stress in humans. Int J Obes (Lond), 30: 400-418. 


\section{Tables}

Table I. General characteristics of subjects.

Anthropometric, biochemical, dietary and lifestyle characteristics ( $n=369)$.

\begin{tabular}{l|ccc}
\hline & Control (n=185) & Obese (n=184) & \\
& Mean (SD) & Mean (SD) & $p$ value \\
\hline Age (y) & $11.5(2.7)$ & $11.5(2.6)$ & 0.824 \\
Males (\%) & 53.0 & 52.7 & 0.961 \\
BMI (kg/m $\left.{ }^{2}\right)$ & $18.9(2.8)$ & $27.7(4.6)$ & $<0.001$ \\
SDS-BMI & $0.2(0.9)$ & $3.8(1.6)$ & $<0.001$ \\
\hline Leptin $(\mu g / L)$ & $11.1(10.7)$ & $36.6(20.5)$ & $<0.001$ \\
Glucose (mmol/L) & $4.7(0.4)$ & $4.9(0.4)$ & $<0.001$ \\
Insulin ( $\mu$ IU/mL) & $8.1(7.2)$ & $17.7(10.5)$ & $<0.001$ \\
HOMA-IR & $1.8(1.7)$ & $3.9(2.4)$ & $<0.001$ \\
Total cholesterol (mmol/L) & $4.3(0.8)$ & $4.2(0.7)$ & 0.418 \\
HDL cholesterol (mmol/L) & $1.6(0.3)$ & $1.3(0.4)$ & $<0.001$ \\
LDL cholesterol (mmol/L) & $2.4(0.7)$ & $2.6(0.6)$ & 0.007 \\
Triglycerides (mmol/L) & $0.7(0.4)$ & $0.9(0.5)$ & $<0.001$ \\
\hline Recreational physical activity & $2.8(5.1)$ & $0.9(1.4)$ & 0.417 \\
(M/S ratio) & 17.0 & 56.5 & $<0.001$ \\
Family history of obesity (\%) & $3199(711)$ & $2849(749)$ & $<0.001$ \\
Energy intake (kcal/day) & $27.3(11.1)$ & $25.6(11.3)$ & 0.025 \\
\hline Fiber (g/d) & $1219.2(655.0)$ & $1177.1(941.6)$ & 0.139 \\
Vitamin A ( $\mu$ g/d) & $210.0(136.2)$ & $178.0(107.5)$ & 0.012 \\
Vitamin C (mg/d) & $9.0(4.4)$ & $7.5(3.5)$ & $<0.001$ \\
Vitamin E (mg/d) & $341.9(126.3)$ & $312.8(107.0)$ & 0.049 \\
Folic acid (mg/d) & & & \\
\hline & & & \\
\hline
\end{tabular}


Table II. Dietary TAC as a measurement of antioxidant intake.

Association of the dietary TAC value as estimated from the food-frequency questionnaire with some antioxidant nutrients intake $(n=369)$. Partial correlations between dietary TAC value and antioxidant daily intake of the subjects were adjusted by age, sex and daily energy intake.

\begin{tabular}{l|cc}
\hline & $\boldsymbol{r}$ & p value \\
\hline Fiber (g/d) & 0.66 & $<0.001$ \\
From vegetables (g/d) & 0.40 & $<0.001$ \\
From fruits (g/d) & 0.50 & $<0.001$ \\
From cereals (g/d) & -0.29 & $<0.001$ \\
From legumes (g/d) & 0.58 & $<0.001$ \\
\hline Vitamin A ( $\mu \mathrm{g} / \mathrm{d})$ & 0.30 & $<0.001$ \\
Vitamin C (mg/d) & 0.78 & $<0.001$ \\
Vitamin E (mg/d) & 0.23 & $<0.001$ \\
Folic acid (mg/d) & 0.76 & $<0.001$ \\
\hline
\end{tabular}


Table III. Characteristics of subjects according dietary TAC.

Anthropometric and biochemical data (mean and SD) for control $(n=185)$ and obese ( $n=184)$ children and adolescents categorized by the median (cut-off 7.8 and $7.0 \mathrm{mmol}$, respectively) of dietary TAC.

\begin{tabular}{|c|c|c|c|c|c|c|}
\hline & \multicolumn{2}{|c|}{$\begin{array}{c}\text { Control } \\
\text { Dietary TAC }\end{array}$} & \multirow[b]{2}{*}{$\begin{array}{c}p \\
\text { value }\end{array}$} & \multicolumn{2}{|c|}{$\begin{array}{c}\text { Obese } \\
\text { Dietary TAC }\end{array}$} & \multirow[b]{2}{*}{$\begin{array}{c}p \\
\text { value }\end{array}$} \\
\hline & $\begin{array}{c}<7.8 \mathrm{mmol} \\
(n=92)\end{array}$ & $\begin{array}{c}>7.8 \mathrm{mmol} \\
(n=93)\end{array}$ & & $\begin{array}{l}<7.0 \mathrm{mmol} \\
(n=92)\end{array}$ & $\begin{array}{c}>7.0 \mathrm{mmol} \\
(n=92)\end{array}$ & \\
\hline $\mathrm{BMI}\left(\mathrm{kg} / \mathrm{m}^{2}\right)$ & $18.9(2.7)$ & $19.1(2.9)$ & 0.718 & $28.4(5.2)$ & $26.9(3.9)$ & 0.032 \\
\hline SDS-BMI & $0.2(0.8)$ & $0.2(0.9)$ & 0.977 & $4.0(1.8)$ & $3.6(1.4)$ & 0.063 \\
\hline Total body fat (\%) & $18.6(7.9)$ & $17.6(8.2)$ & 0.451 & $36.5(7.8)$ & 34.1 (6.9) & 0.032 \\
\hline Leptin $(\mu \mathrm{g} / \mathrm{L})$ & $11.2(11.1)$ & $11.3(10.5)$ & 0.985 & 37.5 (19.8) & $35.8(21.2)$ & 0.580 \\
\hline Glucose (mM) & $4.5(0.5)$ & $4.7(0.4)$ & 0.455 & $4.9(0.4)$ & $5.0(0.4)$ & 0.760 \\
\hline Insulin $(\mu \mathrm{UI} / \mathrm{mL})$ & $7.7(6.0)$ & $8.7(8.3)$ & 0.377 & $19.0(10.8)$ & $16.4(10.1)$ & 0.107 \\
\hline HOMA & $1.7(1.5)$ & $1.9(1.9)$ & 0.491 & $4.2(2.5)$ & $3.7(2.4)$ & 0.130 \\
\hline Total cholesterol (mM) & $4.3(0.8)$ & $4.3(0.7)$ & 0.953 & $4.3(0.6)$ & $4.2(0.7)$ & 0.375 \\
\hline HDL cholesterol (mM) & $1.5(0.3)$ & $1.6(0.3)$ & 0.070 & $1.3(0.3)$ & $1.3(0.4)$ & 0.412 \\
\hline LDL cholesterol (mM) & $2.4(0.6)$ & $2.3(0.7)$ & 0.355 & $2.7(0.6)$ & $2.5(0.6)$ & 0.113 \\
\hline Triglycerides (mM) & $0.7(0.3)$ & $0.7(0.4)$ & 0.937 & $0.9(0.5)$ & $1.0(0.6)$ & 0.656 \\
\hline $\begin{array}{l}\text { Recreational physical } \\
\text { activity (M/S ratio) }\end{array}$ & $2.5(4.9)$ & $3.2(5.3)$ & 0.254 & $0.6(0.7)$ & $1.1(1.8)$ & 0.106 \\
\hline Family history of obesity (\%) & 19.3 & 14.7 & 0.578 & 66.3 & 46.7 & 0.007 \\
\hline Energy intake (kcal/d) & $2993(641)$ & $3460(633)$ & $<0.001$ & 2621 (667) & $3077(760)$ & $<0.001$ \\
\hline
\end{tabular}


Table IV. Dietary TAC associations with obesity-related features.

Multiple linear regression analysis with dietary TAC value (mmol) as an independent variable after adjusting for age, sex, daily energy intake, family history of obesity and recreational physical activity (M/S ratio) of obese children and adolescents ( $n=184)$.

\begin{tabular}{|c|c|c|c|}
\hline & $\begin{array}{c}\text { TAC coefficient } \\
\text { (Confidence Interval 95\%) }\end{array}$ & $R^{2}$ & $P$ value \\
\hline BMI $\left(\mathrm{kg} / \mathrm{m}^{2}\right)$ & $-0.20(-0.41$ to -0.01$)$ & 0.34 & 0.050 \\
\hline SDS-BMI & $-0.09(-0.18$ to -0.01$)$ & 0.07 & 0.043 \\
\hline Total body fat (\%) & $-0.54(-0.92$ to -0.15$)$ & 0.11 & 0.007 \\
\hline
\end{tabular}




\section{Figure legends}

Figure 1. Dietary TAC and total body fat.

Total body fat and dietary TAC values for control $(n=185)$ and obese $(n=184)$ subjects.

Values are means and standard deviations. ${ }^{*} P$ values from Mann-Whitney $U$ test $<0.001$. 